\title{
Vitamin B-complex deficiency and visual acuity
}

\author{
By MALATHI DAMODARAN, K. V. RAMESHWAR SARMA, \\ ACHMAD TIAR AND A. NADAMUNI NAIDU \\ National Institute of Nutrition, Indian Council of Medical Research, \\ Jamai Osmania, Hyderabad - 500 007, India
}

(Received 22 March I978-Accepted I3 July 1978)

\begin{abstract}
I. A study was carried out on 973 school children to find out any relationship between vitamin B-complex deficiency signs and defective vision, and the effect of supplementation of B-complex vitamins on visual acuity.

2. The results of the study showed a significant association between presence of clinical signs of vitamin B-complex deficiency and defective vision.

3. Supplementation with vitamin B-complex was found to have a beneficial effect in improving the visual-acuity status of defective children and in preventing visual defects from developing.

4. It is concluded, therefore, that from the present study it appears that the relationship between vitamin B-complex deficiency and visual defects could be one of 'cause and effect'.
\end{abstract}

Vitamin B-complex deficiency is a common nutritional disorder among children, who constitute approximately $42 \%$ of the population in India (UNICEF, I973). The functional significance of this deficiency has received very little attention, although there is some evidence implicating vitamin B-complex deficiency in producing defective vision (Sood \& Gupta, 1966). Considering the high prevalence of vitamin B-complex deficiency among school children (Vijayaraghavan et al. 197I), a study was undertaken to determine whether there was any association between vitamin B-complex deficiency and defective vision among these children and to assess the effects of supplementation of B-complex vitamins on visual defects, if any.

\section{MATERIALS AND METHODS}

The sample consisted of 973 children of both sexes aged 6-I 5 years from seven schools. The children belonged mostly to low-income-group families residing in rural areas around Hyderabad and engaged in agriculture. All the children attending the school on the day of the initial examination were included in the study. Visual acuity was tested in a well-lit class room using Snellen's ' $E$ ' chart. The subject was made to sit at a distance of $6 \mathrm{~m}$ from the chart and each eye tested separately. The presence of any congenital or acquired defect in the eye was recorded. Visual acuity less than $6 / 6$ in one or both eyes was considered defective vision. A rapid clinical examination was done to detect nutritional deficiency signs with particular reference to vitamin B-complex deficiency signs such as active or healed angular stomatitis, red and raw tongue, atrophic or hypertrophic papillae and cheilosis.

The children were then distributed into one of the following four groups: (A) visual defect alone; (B) visual defect and signs of vitamin B-complex deficiency; (C) signs of vitamin B-complex deficiency alone; (D) no visual defect and no signs of vitamin B-complex deficiency.

Children belonging to groups A and B from four schools received supplements of B-complex vitamins while children belonging to the same groups from three other schools served as controls. Children in group $\mathrm{C}$ from one school were supplemented and the others 
served as controls. All children from group D received no treatment. Visual acuity was tested and clinical status re-assessed I month later on all children from four schools and those belonging to groups A and B in the three other schools.

The supplemented children received one tablet of B-complex vitamins containing (mg): Io thiamin, 5 riboflavin, Io pyridoxine, 50 nicotinamide, 2 calcium pantothenate, Io cyanocobalamin, and 5 folic acid as a separate tablet. On analysis the tablet was found to contain the specified amounts of the components. The supplement was given daily and its consumption ensured.

\section{RESULTS}

\section{Initial examination}

A total of 973 children were examined initially. The prevalence of nutritional deficiency signs were found in 627 children $(64 \cdot 4 \%$ ). Signs of vitamin B-complex deficiency were seen most frequently, occurring in $62.3 \%$ of the children, with Bitot's spots in $3 \%$ of the children and phrynoderma in $1.5 \%$ of the children (Table 1 ).

Mottled enamel, a sign of dental fluorosis, was found in $7 \cdot 6 \%$ of the children and $16 \cdot 9 \%$ were found to suffer from caries.

The results of testing for visual acuity are given in Table 2. Nine children who were found to have visual defects due to obvious anatomic reasons such as leucoma (four), congenital blindness in one eye (one), injury (one), congenital ptosis (one) and Nystagmus (two) were excluded from the study. Two children who were found to have severe impairment of vision $(6 / 60)$ were also excluded from the study.

Altered acuity of vision of varying extents in one or both eyes was found in $143(14.7 \%)$ children, of whom a large majority had only minimal defects.

The association between altered visual acuity and vitamin B-complex deficiency signs is presented in Table 3. Of the 715 children with evidence of vitamin B-complex deficiency, I $26(17 \%)$ had altered acuity of vision whereas of 247 children without signs of vitamin B-complex deficiency only six $(2 \%)$ had altered visual acuity. There was a significant association $(P<0.001)$ between different vitamin B-complex deficiency signs on the one hand and visual defects on the other when the $\chi^{2}$ test was used. (None versus angular stomatitis alone, other B-complex deficiency signs and angular scars.)

\section{'Follow-up' examination}

Of the 132 children who had altered acuity of vision initially, ninety-six were available for re-examination. Seventy of them had received vitamin B-complex supplements while twenty-six had not received any supplement, and had served as controls. The visual acuity status of these children at the end of I month is presented in Table 4 . While fifty-six of seventy supplemented children had shown improvement as judged by a change by one scale in one or both eyes, only four of twenty-six of the unsupplemented children had improved. The difference between the groups was statistically significant $(P<0.001)$.

It has already been mentioned that children having vitamin B-complex deficiency signs, but normal acuity, were divided into two groups: one receiving the supplement and the other serving as controls. The visual acuity status of these children at the end of I month showed that seven of 190 unsupplemented children had developed visual defects, whereas none of the seventy-six supplemented children had developed visual defects (Table 5). However, when the differences in the proportions were tested using Fisher's exact test, they fell short of statistical significance $(P>0.05)$. 
Table I. Distribution of deficiency signs in rural Indian school children aged 6-I 5 years

\begin{tabular}{lcr}
\multicolumn{1}{c}{ Deficiency } & No. of \\
children & \multicolumn{1}{c}{$\%$} \\
Angular stomatitis & 316 & $32 \cdot 47$ \\
Other B-complex vitamin deficiency signs & 290 & $29 \cdot 80$ \\
Bitot's spots & 29 & $2 \cdot 98$ \\
Caries & 164 & $16 \cdot 85$ \\
Mottled enamel & 74 & $7 \cdot 60$ \\
Phrynoderma & 15 & $1 \cdot 54$ \\
No deficiency signs & 346 & $35 \cdot 56$ \\
Total no. of children & 973 &
\end{tabular}

Table 2. Results of visual acuity tests on rural Indian school children aged 6-15 years

\begin{tabular}{|c|c|c|c|c|c|c|c|c|c|}
\hline $\begin{array}{l}\text { Assessment of } \\
\text { visual acuity... }\end{array}$ & $\begin{array}{l}\text { Normal } \\
(6 / 6)\end{array}$ & $6 / 9$ & $6 / 12$ & $6 / 18$ & $6 / 24$ & $6 / 36$ & $6 / 60$ & $\begin{array}{c}\text { Organic } \\
\text { defect }\end{array}$ & Total \\
\hline $\begin{array}{l}\text { No. of children } \\
\%\end{array}$ & $\begin{array}{l}830 \\
85 \cdot 3\end{array}$ & $\begin{array}{l}99 \\
10.2\end{array}$ & $\begin{array}{l}21 \\
2 \cdot 2\end{array}$ & $\begin{array}{l}5 \\
0.5\end{array}$ & $\begin{array}{l}6 \\
0.6\end{array}$ & $\begin{array}{l}I \\
0.1\end{array}$ & $\begin{array}{l}2 \\
0.2\end{array}$ & $\begin{array}{l}9 \\
0.9\end{array}$ & \\
\hline
\end{tabular}

Table 3. Relationship between visual acuity status and vitamin B-complex deficiency in rural Indian school children aged 6-15 years

\begin{tabular}{lcccc}
\multirow{2}{*}{ Visual acuity } & \multicolumn{3}{c}{ Vitamin B-complex deficiency } \\
\cline { 2 - 5 } None & AS alone & Other & Scars \\
Defect & $24 \mathrm{I}$ & 263 & 188 & 138 \\
Total & 6 & 53 & $5 \mathrm{I}$ & 22 \\
Level of significance & 247 & 316 & 239 & 160 \\
& & $<0.001$ & $<0.00 \mathrm{I}$ & $<0.00 \mathrm{I}$
\end{tabular}

AS, angular stomatitis.

Table 4. Effect of vitamin B-complex supplement on the visual acuity status in rural Indian school children aged 6-15 years

$\begin{array}{lccc}\text { Visual acuity status } & \text { Unsupplemented } & \text { Supplemented } & \text { Total } \\ \text { Improved } & 4 & 56 & 60 \\ \text { Not improved } & 22 & 14 & 36 \\ \text { Total } & 26 & 70 & 96 \\ & \chi^{2}=31 \cdot 07(P<0.001) . & \end{array}$

Table 5. Results of 'follow-up' examination of visual-acuity status of supplemented and unsupplemented rural Indian school children aged 6-15 years with only vitamin B-complex deficiency

\begin{tabular}{|c|c|c|c|c|c|c|c|c|}
\hline \multirow{3}{*}{$\begin{array}{l}\text { Vision } \\
\text { defect }\end{array}$} & \multicolumn{8}{|c|}{ Vitamin B-complex deficiency signs at initial examination } \\
\hline & \multicolumn{2}{|c|}{ Angular stomatitis } & \multicolumn{2}{|c|}{ Other signs } & \multicolumn{2}{|c|}{ Scar } & \multicolumn{2}{|c|}{ Pooled } \\
\hline & $\mathbf{S}$ & $\mathbf{U}$ & $\mathbf{S}$ & $\mathbf{U}$ & $\mathbf{S}$ & $\mathbf{U}$ & $S$ & $\mathrm{U}$ \\
\hline+ & 0 & 4 & o & 1 & 0 & $\mathbf{2}$ & $\circ$ & 7 \\
\hline- & 33 & I 2 I & 23 & 28 & 20 & 34 & 76 & 183 \\
\hline
\end{tabular}

S, Supplemented: U, unsupplemented. 


\section{DISCUSSION}

The association between the presence of clinical signs of vitamin B-complex deficiency and altered visual acuity seen at the time of initial examination must be considered significant. Whether the relationship between the two is one of 'association' or whether it is one of 'cause and effect', however, is not easy to decide. The observations that in a great majority of children who had received B-complex vitamin supplements, visual acuity had improved and that in children who had not received the supplement there was no change, suggest that vitamin B-complex deficiency may be involved in causing altered acuity of vision. Such a relationship has been observed by Venkataswamy (1966), who reported a high incidence of nutritional amblyopia in expectant and nursing mothers who showed beneficial effects after administration of B-complex vitamins.

The further observation that B-complex vitamin supplements could not only improve visual acuity, but also prevent altered visual acuity from developing strongly supports a 'cause and effect' relationship. Although the defects were minimal in most of the children, it has to be pointed out that under the conditions of poor lighting and overcrowding that exist in most of the rural schools in India, even minimal defects may prove to be a handicap. The possibility exists that poor vision may lead to poor academic performance and this may, in turn, contribute to the high 'drop-out' rates in rural schools.

The authors are grateful to Dr S. G. Srikantia, Director, National Institute of Nutrition, Hyderabad, India, for his keen interest and guidance throughout the study. They are also grateful to the headmasters of Koheda, Amberpet, Taramathipet, Nagole, Sahebnagar, Anajpur and Injapur schools in Hayatnagar block, Hyderabad District, Andhra Pradesh, India, for their co-operation and the pupils in the schools for their participation in the study.

\section{REFERENCES}

Sood, N. N. \& Gupta, S. (1966). Proc. Natnl. Symp. Nutritional Disorders of the Eye, p. I I5. Hyderabad, India: Sarojini Devi Eye Hospital and Institute of Ophthalmology.

UNICEF (1973). Statistical profile of children and youth in India. New Delhi, India: United Nations Children's Fund (UNICEF).

Venkataswamy, G. (1966). Proc. Natnl. Symp. Nutritional Disorders of the Eye, p. 53. Hyderabad, India: Sarojini Devi Eye Hospital and Institute of Ophthalmology.

Vijayaraghavan, K., Darshan Singh \& Swaminathan, M. C. (197I). Indian J. Med. Res. 59, 648. 